\title{
Theoretical Analysis of The Art Forms of Vocal Music
}

\author{
Ting-ting Chen $^{1, a}$ \\ ${ }^{1}$ Nanyang Institute of Technology, Nanyang, China, 473004 \\ aNylgxychentingting@126.com
}

Keywords: Vocal music, Vocal music theory, The art forms of vocal music

\begin{abstract}
Vocal music, as an art form of music, requires the singers to have not only a certain degree of artistic accomplishment and singing skills, but also a solid theoretical knowledge of vocal music theory. Vocal music theory is one of art forms from the macroscopic point of view. Its function in vocal music is mainly reflected in the general art performance. Therefore, the singing is the external manifestation of vocal music theory. The formation and development of vocal music theory has a direct impact on the overall development of the art forms of vocal music. The existing art forms of vocal music are not based on theory comprehensively, which results in less attention paid to vocal music theory. Therefore, this article would analyze the art forms of vocal music from the perspective of theory and study the manifestations of the art forms of vocal music in theory and the importance of vocal music theory through exploring the functions of vocal music theory in singing from all aspects.
\end{abstract}

\section{Introduction}

Vocal Performing Art is a comprehensive art integrating mentality, physical, imagination and expression. Vocal music, like other kind of arts, is a performance mainly with aesthetic sense and aesthetic principles. Therefore, there are many standards in vocal performance, which can help measure and judge a vocal performance. Among all the standards in vocal performance, vocal music theory is an important one, which shows the wonderful musical performance with the unique charm. With the improvement of people's living standards and knowledge, vocal music art form has been very clear to us, followed by the subjective comments of people on vocal music form. The basic vocal music theory is most important and most concerned. The basic vocal music theory is an cross-field basic theory with the aesthetic principles of authenticity and creativity. Based on theoretical foundation in vocal music, it combines psychology, physiology and physics theory to prefect the performance.

Vocal Performance Arts are not only dependent on training of vocal skills and innate potential, but also requires the singer to pay attention to the basic vocal music theory and emotions of the work in practice. A good singer should have the theoretical knowledge. It is very important for the singer on the concert. Therefore, this article would analyze the art forms of vocal music from the perspective of theory and explore and predict the subsequent vocal music theory.

\section{The Content of Basic Vocal Music Theory}

Basic vocal music theory is to use vocal training to enable students to master the scientific method of voicing. It develops from the beginning's folk style singing to today's music theory, combines the advantages of the various national singing theory and forms the basic vocal theory integrating psychology, physiology, acoustics, physics and vocal linguistics.

The basic vocal theory mainly focuses on reflected the states of singing, including six states, 
specifically larynx state, glottis state, face state, oral state, respiratory state and the overall state.

\section{The Development of The Basic Vocal Music Theory}

Music theory is a product of music development. Broadly speaking, music, as artistic, pleasant, careful voice lined up according to theory to make musical performance perfect, develops form the beginning's wild singing to today's vocal theory.

In ancient societies, vocal music, dance and poetry as the earliest forms of art, develops continuously and creatively into the modern art of music, of which the main content is national vocal music. The national vocal music, with a rapidest development lays a foundation for vocal music theory. The theoretical basis develops from the original Tang Poetry, Song Poem, Yuan Verse, folk songs of Ming and Qing Dynasty. At the beginning, the music includes song, dance and instrument, then fixed pitch gradually emerges, as well as simple scales, obvious and prominent rhythms, thus the vocal music theory gradually develops into the present theory.

\section{The importance of singing in basic vocal music theory}

The knowledge of physiology determines the basic artistry of singing, so it is necessary for the singers to grasp knowledge of psychology, understand the physical structure and working principle when singing and learn sound production function. Singing, as a biological activity, mainly relies on the direction of the central nervous system to accomplish the process of sounding. Meanwhile, in the course of singing, the resonance is dependent on the throat, nasal cavity, pharynx to produce beautiful sounds to match the performance, however, breathing is dependent on the diaphragm and chest. Inspiration should be slow, steady, regular and controllable. ; articulation needs the collaboration of lips, teeth and tongue. In the show, the most important is vocal music is to make most advantages of four organs.

Vocal music psychology plays a very important role in vocal music. Vocal music psychology, a combination of vocal art and psychology, is an inner quality of vocal music skills, reflecting the importance of psychology in vocal music mainly through psychological reactions, brain awareness, imagination, logic of thinking and memory. Vocal music psychology would not only study the psychological characteristics, but also focus on the emotion and temperament when performing on stage. Vocal music art requires the singer to have a good psychological quality. A singer with good psychological quality can better show the artistry of singing. Only the combination of singing and mental activity can make vocal music art perfect, therefore, an singer under excellent physiological circumstances, can improve the vocal music performance and show the artistry of vocal music by learning the psychological theory.

Vocal music performance can determine directly the features of the art forms of vocal music together with physiology, psychology, vocal music physics, linguistics and other related disciplines. Only when the singers grasp the basic knowledge of the above-mentioned subjects and put into use the theory, can they reach the standards of singing and get the praise from the the audience by performances on stage. The singer can improve themselves and get the essence of singing by learning the basic theoretical knowledge, mastering the stage change and adjusting themselves.

\section{The influence of vocal music theory on singing}

The artistry of singing can be reflected by successful vocal music performance. Mere theory or practice is impossible to complete a perfect performance. A singer even with strong skills, still need the guidance by a solid theoretical knowledge. which is reflected in every detail of the singing. It is 
the most attractive part of the process of singing. From the development of vocal music theory, any innovation of theory has made a best interpretation for the singing. The singer should have a good knowledge of basic vocal music theory so as to perform more perfect.

Vocal music art is also known as the art of singing. Its development mainly depends on national singing. Chinese art of singing, based on the national language, specializing in the charm of Chinese traditional opera, is a comprehensive art performance combining with body performance with love, words, and chamber. Basic vocal music theory is a basis of an internal quality of singing. The vocal music theory would have a direct influence on the performance. In practice, the perfect combination of basic vocal music theory of vocal music art would fully embodies the charm of art, which would make the performance more attractive.

\section{The relationship between vocal music theory and vocal music art}

In the singing and performance, the combination of a variety of skills could make a work stand out, but integration of practice and art, voice and emotion, are necessary to improve the artistry of singing. When the singer master it and exhibit on stage, art is attractive. The combination of basic vocal music theory will contribute to the perfect performances, accordingly, the relationship of vocal music and art.

Singing is the main body of vocal music performances, which would has different vocal skills in different artistic expressions. Vocal skills reflects the diversity and complexity of the art forms. The existing vocal skills can be classified mainly by the place of articulation, breathing and intonation. The vocal skills would be analyzed from the perspective of the place of articulation as follows:

Sound production only by voice. Most people produce sound by voice. The singer who employs this kind of sounding in the vocal music performance must have a very strong vocal foundation. In the vocalization practice, the singer would make some slight changes according to the the characteristics of the works to bring his/her superiority into full play. Of course, it also can be used in the situations where there has special emotion such as sadness and remembrance, as well as in pitched works.

Apply the airflow from abdomen to generate abdominal cavity resonance through squeezing, this sounding method generally only be employed in national works or fractions containing mega bass. airflow squeeze will make the vocal sound of the singer completely harmonious with the work, and thus make the artistic expression more appealing. In vocal performance, any change of airflow in the singer's body would directly affect the singing. So abdominal cavity resonance method would make the performance more influential and appealing.

The the vocal skill of cranial cavity resonance is one of the methods generally used by the singer. Its most important feature that it is widely used in the Bel Canto and the high notes in national singing. The selection of vocal skills determines the art, which determines the form of performance. Therefore the vocal skills and the form of performance are closely related, can not be separated. It is necessary to combine art and vocal skills in theory.

Art is the focus of the stage, and breathing is the manifestation of art. Every aspect of the singing on the stage are mainly the show of breathing. The singer would make a pleasing vocal performance on the stage by combining the breathing and its own advantages. Different vocal performances on stage should employ different approach to express emotion, which requires appropriate transition during the singing to achieve the art purpose of performance. Appropriate planning to breathe as a essential skill could make the vocal music performance perfect. Every breathing detail would be perfect in vocal music performance only when breathing and art are fully integrated. There are three ways to integrate breathing method and art as follows 
The overall combination of breathing method and vocal works. The overall artistry of vocal works is conveyed mainly through syllables, melody, timbre, and emotion. In the selection process of breathing, the combination of breathing method and vocal works have a great influence on the overall performance. Therefore, it is the basis for the follow-up vocal performance to master this method.

The combination of breathing method and the artistic expression of vocal music work. A perfect music work should be the perfect combination of breathing method and art. The close and unique combination of breathing and art should be based on emotional tone and singing speed of the work. Therefore the singer can grasp the breathing rate and strength accurately in the singing and control the running of breath to better convey the artistic charm of the work.

The combination of breathing method and the post of singer. On the stage, the combination of breathing method and the post of singer would bring a certain change on the post, which would leads to the changes in artistic expression. It can be manifested through the combination of breathing and artistic expression. In a specific singing practice, the breathing technique should be determined first, and then the artistic expression of the work should be analyzed, and finally the balance should be assured through the combination, and will be performed perfectly on the stage.

Good intonation as one of the most important requirements in vocal music. is the basic quality of a excellent singer. The combination of intonation and art is not only conducted according to the characteristics of the work but also according to the characteristics of the singer. Everyone may employs a particular way to grasp the intonation. It is the determinant for evaluating whether the singing is successful or that how excellently the singer control the intonation on the stage. Therefore, it is very important for the singing to optimize the combination of intonation and artistic expression.

\section{Conclusion}

Vocal music has become a necessity of live. Its forms are diversified. The art form of vocal music id a combination of theory and art. The audience would feel the same way with the singers by watching their various actions and admire the communication of music. Then the audience would appreciate the performance and enjoy the music. But it requires the perfect combination of theory and art. There are a variety of theories in vocal music. The art performance is to convey the charm of vocal music on the stage based on theory and the characteristics of the singer.

This article has analyzed the complex relationships between the vocal music theory and the art performance, which would provides with some guidance in the future theoretical teaching and vocal music performance. Through the analysis of the relationship between vocal music and the vibrate organ, respiratory organ, resonance organ, enunciation organ as well as vocal articulation, breathing methods and intonation, this article introduced the necessity of vocal music theory to the art form of vocal music performance. Form the perspectives of psychology, physiology, acoustics, physics and linguistics, this article studied the relationships between the vocal music theory and the art form of vocal music performance and the importance of vocal music theory to the art form of vocal music performance. The singer's knowledge of theory is mainly reflected in the state of singing. The perfect combination, from the perspective of the art forms, created a atmosphere for the audience to feel the charm of art from multiple angles and multiple levels, improving the art forms of vocal music performance to some extent.

\section{References:}

[1] Zhang. The Importance of Learning Theoretical Knowledge of Sound [J]. Popular Literature, 
2014-01-30

[2] Yao Dan The Necessity for the Sound Theory Course [J]. Music Live , 2008-02-01

[3] Liang Xiaocheng Literature Review of National Sound Theory From 2000 to 2010 [D] Wuhan Conservatory of Music, 2012-06

[4] Tian Dandan. Studies on Binding of Physiology and Psychology in Vocal Music Singing [D]. Shanxi Normal University, 2015-04

[5] Wang Guobin. Sound and Emotion of Vocal Music[D]. Chinese Academy of Music, 2010-05

[6] Minglan. Research on Phone Interface Design for Schoolchildren [D]. Nanjing University, 2012-04

[7] Zhao Qing. Personalization of Vocal Music Art [J]. Chinese music, 2002-10-3

[8] Xing Fang Fang. Reseach on Relationships Between Singing and vocal music work [D]. Central China Normal University, 2009-05-01

[9] Wang Wenchun The Role of Vocal Music in Intonation Training [J]. TRIBUNE, 2010 